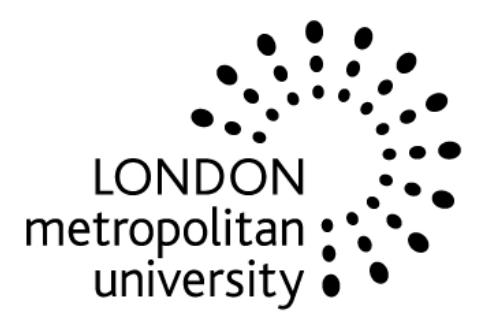

Centre for International Capital Markets

Discussion Papers

ISSN 1749-3412

Fiscal Shocks and Real Exchange Rate Dynamics:

Some Evidence for Latin America

Guglielmo Maria Caporale, Davide Ciferri and Alessandro Girardi

No 2008-5 


\title{
FISCAL SHOCKS \\ AND REAL EXCHANGE RATE DYNAMICS: SOME EVIDENCE FOR LATIN AMERICA
}

\author{
Guglielmo Maria Caporale ${ }^{\mathrm{a}}$, Davide Ciferri $^{\mathrm{b}}$ and Alessandro Girardi ${ }^{\mathrm{b}, \mathrm{c}}$ \\ ${ }^{a}$ Brunel University, London \\ ${ }^{b}$ University Tor Vergata, Rome \\ ${ }^{c}$ Institute for Economic Studies and Analyses, Rome
}

February 2008

\begin{abstract}
This paper analyses the effects of fiscal shocks using a two-country macroeconomic model for output, labour input, government spending and relative prices which provides the orthogonality restrictions for obtaining the structural shocks. Dynamic simulation techniques are then applied, in particular to shed light on the possible effects of fiscal imbalances on the real exchange rate in the case of six Latin American countries. Using quarterly data over the period 1980-2006, we find that in a majority of cases fiscal shocks are the main driving force of real exchange rate fluctuations.
\end{abstract}

JEL Classification: $C 32, E 62, O 54$.

Keywords: Fiscal shocks, real exchange rate, Latin American countries.

Corresponding author: Professor Guglielmo Maria Caporale, Centre for Empirical Finance, Brunel University, Uxbridge, Middlesex UB8 3PH, UK. Tel.: +44 (0)1895 266713. Fax: +44 (0)1895 269770. Email: Guglielmo-Maria.Caporale@brunel.ac.uk 


\section{Introduction}

In recent years, the macro-economic effects of fiscal shocks have been extensively analysed in the empirical literature (Hemming et al., 2002). Some studies have applied Vector AutoRegression (VAR) methods previously used to analyse the effects of unanticipated monetary impulses. Fiscal shocks have usually been modelled by imposing sign restrictions on the impulse responses (Mountford and Uhlig, 2005), by relying on a Choleski ordering with the fiscal variable appearing first (Favero, 2002), or by exploiting decision lags in fiscal policy and institutional information about the elasticity of fiscal variables to economic activity within a structural VAR framework (Blanchard and Perotti, 2002). Based on the 'narrative approach' of Romer and Romer (1989), another strand of literature has pursued an alternative route where specific exogenous fiscal episodes are isolated through dummies (Burnside et al. 2004, and Christiano, et al. 1999, among others).

Despite this growing empirical literature, there is still no consensus on the size or even the sign of the effects of fiscal shocks on output or the real exchange rate. A possible explanation are the difficulties involved in their identification. As pointed out in Mountford and Uhlig (2005), standard problems encountered in the application of the VAR methodology to assess the effects of fiscal shocks are the following: $i$ ) how to distinguish movements in fiscal variables which are caused by fiscal policy shocks from those in response to other shocks; ii) how properly to define fiscal shocks; iii) the existence of a temporal lag between the announcement and the implementation of fiscal policy. The narrative approach makes it possible to circumvent potentially controversial identifying assumptions (typical of the VAR approach), but it has the drawbacks that these episodes could be in part anticipated or that substantial fiscal shocks, of different type or sign, could have occurred around the same time (Perotti, 2002).

In general, all these studies have mainly focused on developed countries and within a closed-economy setup, while the literature on the international transmission of fiscal policy has been almost exclusively theoretical (Baxter, 1992; Bianconi and Turnovsky, 1997; Obstfeld and Rogoff, 1995). An exception is a recent empirical paper by Arin and Koray (2008), who investigate how US fiscal shocks affects the US economy and how 
they are transmitted to Canada. In the present paper, we focus instead on the effects of fiscal shocks on international competitiveness (the bilateral real exchange rate vis-à-vis the US dollar) in six Latin American (LA) countries (namely, Argentina, Bolivia, Brazil, Chile, Mexico and Peru), over the period 1980-2006. Since the seminal contribution of Krugman (1979), it is well known among international economists that most of the LA countries suffered speculative attacks on their currencies from international investors mainly because of inconsistencies between domestic macroeconomic policies and the adopted exchange rate regime. In turn, real exchange rate misalignments have often led to macroeconomic disequilibria, and hence the correction of external imbalances might require both demand management policies and real exchange rate devaluations (see, among others, Edwards, 1988). As a result, equilibrium real exchange rates have changed over time, periods of large appreciations being followed by severe depreciations or periods of stability. Furthermore, real exchange rate variability in the LA countries over the eighties was greater than almost anywhere else in the world (Edwards, 1989), owing to debt crises that resulted in a real depreciation of the domestic currency, with frequent devaluations and inflationary episodes.

To the best of our knowledge, the effects of fiscal shocks on the real exchange rates in the LA countries are yet to be investigated in the literature. Previous analyses of the sources of real exchange rate fluctuations have typically focused on the role of real demand (Enders and Hurn, 1994), monetary (Clarida and Gali, 1994; Weber, 1997) or productivity (Alexius, 2005) shocks, and have overlooked the possible effects of fiscal unbalances on countries' international competitiveness. Notable exceptions are the studies of Obstfeld (1993) and Asea and Mendoza (1994), where, in contrast to more traditional monetary approaches, the focus is on the role of fiscal policy and other real variables (such as productivity shocks) in real exchange rate models. Further, only a few studies (Chowdhury, 2004; Hoffmaister and Roldós, 2001) have investigated the sources of real exchange rates fluctuations in developing economies, mainly relying on the approach proposed by Blanchard and Quah (1989) to assess the relative contribution of temporary and permanent disturbances, while the recent paper by Rodríguez and Romero (2007) explicitly analyses the permanent/transitory decomposition of real exchange rates in four LA countries. 
We adopt a framework which allows for a wide range of (structural) shocks potentially affecting the real exchange rate. Specifically, we employ a two-country macroeconomic model for output, labour input, government spending and relative prices, along the lines of the studies by Ahmed et al. (1993) and Hoffmaister and Roldós (2001), where the modelling approach to macroeconomic fluctuations developed by Blanchard and Quah (1989) is extended to an open-economy setting allowing for the possible existence of cointegration relationships among the variables of the system. The theoretical model consists of four blocks linked to each other according to a quasirecursive scheme, and provides the orthogonality restrictions to be imposed to achieve the identification of the structural shocks. These disturbances are identified as supply-side (relative productivity and relative labour inputs) and demand-side (relative fiscal and relative preference) shocks. Their dynamic effects on the real exchange rate are then examined within a structural Vector Error Correction (VEC) framework by means of dynamic simulation (such as forecast variance error decomposition and impulse response analysis) and historical decomposition techniques.

Using quarterly data over the period 1980-2006, we provide clear evidence that fiscal shocks are a key determinant of real exchange rate dynamics for most of the LA countries we consider. However, the sign and the size of the effects of unanticipated fiscal impulses on the level of the real exchange rate vary, reflecting different degrees of productivity of government expenditure. Further, using alternative econometric specifications, we show that the contribution of demand shocks to explaining real exchange rate fluctuations increases when shorter cyclical fluctuations are taken into account. Finally, omitting the cointegration relationships, which we show exist, is found to lead to overestimating the role of demand shocks and underestimating the contribution of fiscal disturbances.

The layout of the paper is as follows. Section 2 describes the econometric model. Section 3 presents the empirical results. In Section 4, dynamic simulations based on forecast error variance and historical decompositions are discussed, while robustness analysis is reviewed in Section 5. Some final remarks follow in Section 6. 


\section{The model}

The framework adopted in this Section enables us to study the sources of macroeconomic fluctuations in a bipolar world for a group of six LA economies (namely, Argentina, Bolivia, Brazil, Chile, Mexico and Peru). In line with previous empirical papers on these countries, we assume that the US economy is the relevant foreign country (Berg et al., 2002; Ahmed, 2003). The chosen model aims to provide a theoretical structure to analyse the role of supply and demand shocks (with particular emphasis on fiscal disturbances) in explaining the fluctuations of the real exchange rate, one of the most common indicators of international competitiveness. This allows us to go beyond the dichotomy between permanent/supply and transitory/demand shocks previously explored in the literature on real exchange rate determination in the developing countries (Chowdhury, 2004; Rodríguez and Romero, 2007).

\subsection{Economic relationships}

We analyse the dynamic interactions between the domestic economy and the US using a stylised long-run model, which consists of four blocks linked to each other according to a quasi-recursive scheme. Following Ahmed et al. (1993) and Hoffmaister and Roldós (2001), we rely exclusively on long-run restrictions, which can be directly derived from macroeconomic theory (unlike short-run ones, which can therefore be controversial). In what follows, the suffix $i(j)$ indicates domestic (US) variables, while $t$ indexes time. All variables are expressed in logarithms.

We start by defining a standard production function in the spirit of Binder and Pesaran (1999) and Garratt et al. (2003):

$$
y_{i t}=\alpha_{1 i}+n_{i t}+\alpha_{2 i} \theta_{i t}^{y}, y_{j t}=\alpha_{1 j}+n_{j t}+\alpha_{j} \theta_{j t}^{y}
$$

where $y$ 's, $\alpha_{1}$ 's, $n$ 's indicate total real output, a generic deterministic component (e.g., an intercept and a linear trend) and labour inputs, respectively, while the $\theta^{y}$ 's represent technology shocks driving real output over time. From the equations in (1), relative labour productivity can be expressed as:

$$
\pi_{t} \equiv\left(y_{i t}-n_{i t}\right)-\left(y_{j t}-n_{j t}\right)=\alpha+\phi_{t}
$$


where $\alpha=\left(\alpha_{1 i}-\alpha_{1 j}\right)$ and $\phi_{t}=\left(\alpha_{2 i} \theta_{i t}^{y}-\alpha_{2 j} \theta_{j t}^{y}\right)$ represents the relative technology shock.

In the long run labour inputs are expected to respond to country-specific exogenous shocks originating in the labour market and/or from permanent changes in government supply policies. Accordingly, we can write down the following functional form for both labour input levels:

$$
n_{i t}=\beta_{1 i}+\beta_{2 i} \theta_{i t}^{n}, n_{j t}=\beta_{1 j}+\beta_{2 j} \theta_{j t}^{n}
$$

where the $\beta_{1}$ 's indicate deterministic components, and the $\theta^{n}$ 's represent idiosyncratic labour-supply disturbances. Hence, the relative employment level, $n_{t}$, can be expressed as:

$$
n_{t} \equiv n_{i t}-n_{j t}=\beta+\mathrm{v}_{t}
$$

where $\beta=\left(\beta_{1 i}-\beta_{1 j}\right)$ and $v_{t}=\left(\beta_{2 i} \theta_{i t}^{n}-\beta_{2 j} \theta_{j t}^{n}\right)$ is the relative labour-supply shock.

Having defined the stochastic disturbances driving relative labour productivity and relative labour inputs, we move on to modelling the public sector of the two economies. Let $\tilde{g}$ be government size (defined as the ratio of government purchases of goods and services to output); taking the (log of) private output (the difference between total output and government spending) in the two economies, $y^{P}$, and using the approximation $\ln (1-x) \cong x$ we obtain the following relationships:

$$
y_{i t}^{P}=y_{i t}-\tilde{g}_{i t}, y_{j t}^{P}=y_{j t}-\tilde{g}_{j t}
$$

As in Ahmed et al. (1993), the size of domestic (foreign) government depends both on domestic and foreign permanent fiscal policy shocks, the $\theta^{y^{P}}$ parameters, through a feedback reaction function governed by the $\gamma_{2}$ 's which measure the response to an exogenous change in the foreign (domestic) government size:

$$
\tilde{g}_{i t}=\gamma_{1 i}+\theta_{i t}^{y^{P}}+\gamma_{2 i} \theta_{j t}^{y^{P}}, \tilde{g}_{j t}=\gamma_{1 j}+\theta_{j t}^{y^{P}}+\gamma_{2 j} \theta_{i t}^{y^{P}}
$$

where the $\gamma_{1}$ 's are constant quantities. Using equations (5) to substitute into (4) we then obtain:

$$
y_{i t}^{P}=\gamma_{1 i}+y_{i t}+\theta_{i t}^{y^{P}}+\gamma_{2 i} \theta_{j t}^{y^{P}}, y_{j t}^{P}=\gamma_{1 j}+y_{j t}+\theta_{j t}^{y^{P}}+\gamma_{2 j} \theta_{i t}^{y^{P}}
$$

or, in relative terms: 


$$
z_{t} \equiv y_{i t}{ }^{P}-y_{j t}{ }^{P}=\left(y_{i t}-y_{j t}\right)+\left(\varphi_{t}-\gamma\right)
$$

where $\gamma=\gamma_{1 i}-\gamma_{1 j}$ and $\varphi_{t}=\left[\left(1-\gamma_{2 i}\right) \theta_{j t}^{y^{p}}-\left(1-\gamma_{2 j}\right) \theta_{i t}^{y^{p}}\right]$ represents the relative fiscal shock. Using conditions (2) and (3), we can express relative private output as a linear function of the structural shocks:

$$
z_{t}=\alpha+\beta-\gamma+\phi_{t}+v_{t}+\varphi_{t}
$$

Finally, consumers in both economies are assumed to make their consumption decisions to maximise their utility. Adopting a log-linear specification with identical preferences in the two countries, the closed-form solution is such that the (log of) relative prices, $q_{t}$, equals the marginal rate of substitution (Ahmed et al., 1993). In turn, the balanced-growth path implies that the ratio of world consumption of each good to total private output of that good is constant $(d)$, ensuring that the following condition holds:

$$
q_{t}=\delta+\left(\theta_{j t}^{q}-\theta_{i t}^{q}\right)+\left(y_{i t}^{P}-y_{j t}^{P}\right)
$$

where the $\theta^{q}$ 's are time-varying preference shocks entering the agents' utility function. Let $\eta_{t}=\left(\theta_{j t}^{q}-\theta_{i t}^{q}\right)$ be the relative preference shock. Combining (6) and (7), we can express the real exchange rate as:

$$
q_{t}=\alpha+\beta-\gamma+\delta+\phi_{t}+v_{t}+\varphi_{t}+\eta_{t}
$$

Equation (8) expresses real exchange rate dynamics as a combination of the underlying disturbances, which are left unrestricted to encompass a large number of competing theories of real exchange rate determination. Choosing a theory rather than another is thus an empirical issue to be determined by the data. Suppose, for instance, that supply-side shocks dominate the dynamics of the $q_{t}$ variable. This would support empirically the Harrod-Balassa-Samuelson (HBS) view of real exchange rate determination. ${ }^{1}$ Consider, instead, the case where $\varphi_{t}$ turns out to be the most relevant source of real exchange rate fluctuations. This would give empirical support to the model of Roldós (1995), within which public spending shocks can lead to permanent shifts in the real exchange rate. Next suppose that preference shocks are the main driving factor of

\footnotetext{
${ }^{1}$ See Sarno and Taylor (2002) and Alexius (2005) for the empirical content of this paradigm for developing and industrialised economies.
} 
$q_{t}$. This would be consistent with a general equilibrium, two-country models with a representative utility-maximising agent in the presence of cash-in-advance constraints (Stockman, 1980; Lucas, 1982). Clearly, any of the above-mentioned theoretical hypotheses could be a plausible explanation for the behaviour of the real exchange rate in the LA countries. However, were $q_{t}$ to depend only on constant terms, this would put into question the empirical validity of the purchasing power parity (PPP) hypothesis, and would be more difficult to rationalise. Recent surveys covering this issue are Sarno and Taylor (2002) and Taylor (2006).

\subsection{Steady-state of the model}

We assume that the four variables (relative productivity, relative labour input, relative private output and real exchange rate) are driven by three common stochastic trends $\left(\phi_{t}\right.$, $v_{t}$ and $\left.\varphi_{t}\right)$ in the long-run. These trends evolve over time according to the following laws of motion:

$$
\phi_{t}=\phi_{t-1}+\varepsilon_{t}^{\phi}=\phi_{0}+\sum_{i=1}^{t} \varepsilon_{i}^{\phi}, v_{t}=v_{t-1}+\varepsilon_{t}^{v}=v_{0}+\sum_{i=1}^{t} \varepsilon_{i}^{v}, \varphi_{t}=\varphi_{t-1}+\varepsilon_{t}^{\varphi}=\varphi_{0}+\sum_{i=1}^{t} \varepsilon_{i}^{\varphi}
$$

where $\phi_{0}, \mathrm{v}_{0}$ and $\varphi_{0}$ denote initial conditions and the $\varepsilon$ 's are uncorrelated white-noise processes such that $E\left(\varepsilon_{t}^{l}\right)=0, E\left(\varepsilon_{t}^{l}\right)^{2}=\sigma_{\varepsilon^{l}}^{2}, E\left(\varepsilon_{t}^{l} \varepsilon_{s}^{l}\right)=0$ for $s \neq t$, with $l=\phi, \cup, \varphi$. The model also contains the transitory stochastic component $\eta_{t}$, which is assumed to be orthogonal with respect to $\varepsilon_{t}^{\phi}, \varepsilon_{t}^{0}$ and $\varepsilon_{t}^{\varphi}$ and obeys the following law of motion:

$$
\eta_{t}=\rho \eta_{t-1}+\varepsilon_{t}^{\eta}=\varepsilon_{t}^{\eta} /(1-\rho L), \rho<1
$$

where $\varepsilon_{t}^{\eta}$ is an uncorrelated white noise process.

To find the steady state of the model, the initial values of all the permanent shocks $\left(\phi_{0}, \cup_{0}\right.$ and $\left.\varphi_{0}\right)$ along with the deterministic component of all the variables of the theoretical model $(\alpha, \beta, \gamma, \delta)$ are set equal to zero. Accordingly, the steady state can be represented as follows: 


$$
\left[\begin{array}{c}
\pi_{t} \\
n_{t} \\
z_{t} \\
q_{t}
\end{array}\right]=\left[\begin{array}{lll}
1 & 0 & 0 \\
0 & 1 & 0 \\
1 & 1 & 1 \\
1 & 1 & 1
\end{array}\right] \cdot\left[\begin{array}{c}
\phi_{t} \\
v_{t} \\
\varphi_{t}
\end{array}\right]
$$

The long-run structure (9) implies that not only shocks originating from the supplyside of the economy but also demand shocks (namely, fiscal shocks) can induce permanent shifts of the steady state of the system. By contrast, relative preference shocks are assumed to have transient effects on the levels of the variables. This assumption can be rationalised in terms of the transitory nature of shocks driving demand for domestic and foreign (aggregate) goods. ${ }^{2}$ Note that our framework allows for different representations without changes in the causality order of the variable and any loss in generality, with the restrictive assumption of cointegration not being strictly required to achieve identification. ${ }^{3}$ On the other hand, testing for cointegration is a relevant empirical issue in modelling real exchange rate fluctuations (Alexius, 2005).

\subsection{Innovation accounting}

Equations (2)-(3)-(6)-(8) represent the building-blocks to study the interactions between domestic and foreign economies. Adopting the same notation as above, we focus on the following $k$-dimensional VAR model in error correction form:

$$
\left[\begin{array}{c}
\Delta \pi_{t} \\
\Delta n_{t} \\
\Delta z_{t} \\
\Delta q_{t}
\end{array}\right]=c+\Pi\left[\begin{array}{c}
\pi_{t-1} \\
n_{t-1} \\
z_{t-1} \\
q_{t-1}
\end{array}\right]+\sum_{i=1}^{p-1} \Gamma_{i}\left[\begin{array}{c}
\Delta \pi_{t-i} \\
\Delta n_{t-i} \\
\Delta z_{t-i} \\
\Delta q_{t-i}
\end{array}\right]+\left[\begin{array}{c}
u_{t}^{\pi} \\
u_{t}^{n} \\
u_{t}^{z} \\
u_{t}^{q}
\end{array}\right], u_{t} \sim N\left(0, \Sigma_{u}\right)
$$

where $c$ is a vector of deterministic components, the $\Gamma$ 's are matrices of autoregressive parameters, $\Delta$ is the first difference operator and the vector $u_{t}=\left[\begin{array}{llll}u_{t}^{\pi} & u_{t}^{n} & u_{t}^{z} & u_{t}^{q}\end{array}\right]^{\prime}$ contains the estimated residuals. Given our theoretical assumptions, we expect the long-

\footnotetext{
${ }^{2}$ As discussed below, the data are broadly consistent with the empirical specification outlined in this Section.

${ }^{3}$ For instance, allowing for permanent shifts in demand between domestic and foreign goods would amount to introducing an additional stochastic trend into the system (Ahmed et al., 1993; Hoffmaister and Roldós, 2001). The model would then exhibit four common trends and no cointegration among the variables.
} 
run matrix $\Pi$ to have rank one, i.e. the presence of one cointegrating vector in model (10).

Structural identification is achieved following the common trends methodology (Warne 1993). Omitting the deterministic component, the reduced-form moving average (MA) representation of the model defines the data generating process (DGP) as a function of the initial conditions (set equal to zero for the sake of exposition) and of the reduced-form shocks $u$ 's. This is given by:

$$
x_{t}=C \sum_{i=1}^{t} u_{i}+C^{*}(L) u_{t}
$$

where the matrix $C$ measures the impact of cumulated shocks to the system, $C^{*}(L)$ is an infinite polynomial in the lag operator $L$, and $u_{t}=\left[\begin{array}{llll}\pi_{t} & n_{t} & z_{t} & q_{t}\end{array}\right]^{\prime}$.

The reduced form and the structural residuals are linked through the relationship $u_{t}=B \varepsilon_{t}$, where $B$ is a non-singular matrix (Warne, 1993). Hence, the structural MA representation is the following:

$$
x_{t}=\Phi \sum_{i=1}^{t} \varepsilon_{i}+\Phi^{*}(L) \varepsilon_{t}
$$

where the matrix $\Phi=C B$ represents the permanent component of the model, and the matrix polynomial $\Phi^{*}(L)=C^{*}(L) B$ the transitory or cyclical component. Structural identification allows to decompose each of the four time series into the sum of distinct components driven by structural shocks. Focusing on the real exchange rate, $q_{t}$, we have $q_{t}=q_{t}^{\phi}+q_{t}^{\mathrm{v}}+q_{t}^{\varphi}+q_{t}^{\eta}$ with:

$$
\begin{aligned}
& q_{t}^{\phi}=\Phi_{41} \sum_{i=1}^{t} \varepsilon_{i}^{\phi}+\sum_{i=1}^{t} \Phi_{i, 41}^{*} \varepsilon_{i}^{\phi}, \quad q_{t}^{\mathrm{v}}=\Phi_{42} \sum_{i=1}^{t} \varepsilon_{i}^{\mathrm{v}}+\sum_{i=1}^{t} \Phi_{i, 42}^{*} \varepsilon_{i}^{\mathrm{v}}, \\
& q_{t}^{\varphi}=\Phi_{43} \sum_{i=1}^{t} \varepsilon_{i}^{\varphi}+\sum_{i=1}^{t} \Phi_{i, 43}^{*} \varepsilon_{i}^{\varphi}, q_{t}^{T}=\sum_{i=1}^{t} \Phi_{i, 44}^{*} \varepsilon_{i}^{\eta},
\end{aligned}
$$

respectively, where $\Phi_{j k}$ is the element in the $j$-th row and $k$-th column in $\Phi$, and $\Phi_{i, j k}^{*}$ that in the $j$-th row and $k$-th column in the matrix $\Phi_{i}^{*}$ which forms the polynomial $\Phi^{*}(L)$ in $(11)$.

The decomposition (12) makes it possible to assess to what extent each of the four stochastic elements included in the model contributes to explaining the evolution of the 
real exchange rate (and the other variables of the system) over time. Once the model has been identified, dynamic simulations (such as forecast error variance decomposition and impulse analysis) and historical decomposition can be performed.

\section{Data and estimation results}

\subsection{Data sources and construction of variables}

Quarterly observations over the period 1980q1-2006q4 are used. Data for the nominal exchange rate $(E)$, defined as national currency per US dollar, consumer price index $(P)$ and real GDP $(Y)$ are from the IMF's International Financial Statistics (IFS) database (code AE...ZF, 64...ZF and 99BVP...RZF, respectively). For Argentina and Brazil these data were obtained from Datastream. Employment levels $(N)$, measured in thousand of employees, are taken from Datastream for all countries. Finally, the shares of government expenditure in good and services $(G)$ are from Penn World Table 6.2. When quarterly observations are not available, annual data have been interpolated to create quarterly series using the TSP package. Finally, seasonal adjusting has been carried out using TRAMO/SEATS. Private output is obtained by multiplying the level of real GDP for the share of private output calculated as $(1-G)$. The real exchange rate $(Q)$ is defined as $E$ times the ratio between US and domestic prices. Thus, an increase in $Q$ means a real depreciation. All the variables are expressed in constant prices (base year 2000=1). Table 1 below provides further details.

\section{Table 1}

As a preliminary analysis, we performed standard ADF (Dickey and Fuller, 1979) unit root tests on (the log of) each variable. The deterministic component includes an intercept and, when statistically significant, a linear trend. The number of lags is chosen such that no residual autocorrelation is evident in the auxiliary regressions. In all cases we are unable to reject the unit root-null hypothesis at conventional nominal levels of significance. On the other hand, differencing the series appears to induce stationarity. The 
PP (Philips and Perron, 1988) unit root test and the KPSS (Kwiatkowski et al. 1992) stationarity test corroborate these results. ${ }^{4}$

\section{Table 2}

\subsection{Baseline specification: VEC model estimates}

The order of autoregression of the models is chosen according to the usual optimal lag length criteria (Akaike information criterion, AIC, and Bayesian information criterion, BIC), setting the maximum lag equal to eight. In the case of discordant results between the alternative criteria, we give preference to the AIC to allow for a richer system specification. The order of autoregression turns out to be two for Mexico, three for Chile, four for Argentina and Brazil, five for Peru and eight for Bolivia. System misspecification tests (not reported to save space) suggest no traces of heteroskedasticity and serial correlation. ${ }^{5}$ Departures from normality are detected in all models. However, as pointed out by Lee and Tse (1996), the maximum likelihood approach to cointegration developed by Johansen (1995) produces testing procedures which are fairly robust to the presence of non-normality.

The number of cointegration vectors is determined on the basis of the trace test statistics of Johansen (1992). Their critical values are taken from Osterwald-Lenum (1992). Notice that the VAR specification considered here is model $H_{1}^{*}(r)$ in Johansen's notation, where a linear deterministic trend is implicitly allowed for, but this can be eliminated by the cointegrating relations so that the process contains no trend stationary components. Table 3 presents the results. The trace test suggests the presence of one cointegration relationship in all models at the 5 percent level of significance, except in the case of Bolivia where the test suggests choosing a rank of two, but a single long-run equilibrium condition at the 1 percent. These results are broadly consistent with our $a$

\footnotetext{
${ }^{4}$ Results from the PP and KPSS tests are not reported to save space, but are available from the authors upon request.

${ }^{5}$ Only in the case of Bolivia are there symptoms of autocorrelation, mainly in the equations for relative productivity and relative labour services.
} 
priori theoretical assumptions about the existence of (at least) three common stochastic trends driving each system. ${ }^{6}$

\section{Table 3}

Structural residuals are then extracted from the reduced-form disturbances by imposing (at least) $k^{2}=16$ restrictions on the elements of matrix $B$. A first set of constraints is obtained by assuming that the structural shocks are orthonormal: this implies $k(k+1) / 2=10$ (non-linear) restrictions. The choice of the cointegration rank allows to distinguish transitory shocks from permanent innovations and produces additional $r(k-r)=3$ restrictions; in our case, there are four additional zero restrictions in the $4 \times 3$ matrix in (9), producing an over-identified structure, which can be tested by means of the usual $\chi^{2}$-distributed likelihood ratio (LR) tests. The statistics for Argentina, Bolivia, Chile and Mexico turn out to be 1.28, 0.68, 0.37 and 1.60 respectively; by contrast, in the case of Brazil and Peru, their value is 263.20 and 140.81, respectively. By comparing these test statistics to the critical values of a $\chi^{2}$ distribution with one degree of freedom, we are unable to reject the null hypothesis of the validity of the overidentifying restriction only for the first four models. Accordingly, we impose the overidentified structure in the case of Argentina, Bolivia, Chile and Mexico, while for the Brazilian and Peruvian systems we employ a just-identified structure.

\section{Empirical evidence}

Once structural and data-consistent identification of the VEC models is achieved, dynamic simulations (forecast error variance decomposition and impulse response analysis) as well as historical decomposition exercises can be performed. We employ these techniques in order to address three main issues: first, we assess the role played by the underlying (structural) sources in explaining the fluctuations of the variables in each

\footnotetext{
${ }^{6}$ The maximum eigenvalue test statistics indicate one cointegrating relationship only for three countries (Argentina, Bolivia and Peru), while in the other models (Brazil, Chile and Mexico) there is evidence of four common stochastic trends. In general, we favour the conclusions of the trace test in line with Johansen (1992), according to which the maximum eigenvalue test may produce a non-coherent testing strategy. Results are available on request.
} 
country model, also discriminating between supply and demand disturbances (Section $4.1)$; second, we study the sign and the magnitude of the response of the real exchange rate to an unanticipated fiscal shock (Section 4.2); third, we analyse the contribution of each structural shock in driving real exchange dynamics over the sample period under investigation (Section 4.3).

\subsection{Sources of system-wide and variable fluctuations}

Several studies have analysed the role of demand shocks (for instance, monetary and fiscal policies) and supply disturbances (productivity and labour supply shocks or structural restructuring policies, such as tariff and trades reforms) in a closed-economy context, both at the aggregate (Blanchard and Quah, 1989; Gali, 1999, among others) and, more recently, at the disaggregate level (Chang and Hong, 2005; Busato et al., 2005) for the US economy or other developed countries. We assess the relative contribution of the structural shocks in explaining macroeconomic fluctuations by means of forecast error variance decomposition analysis. Such a tool makes it possible to summarise the information contained in the structural MA representation (11) and provides a convenient measure of the relative importance of each shock to forecast error variance as a function of the simulation horizon. Table 4 presents the share of variability (in percentage terms) which can be attributed to each structural shock for the individual variables of the model as well as for the system as a whole (row labelled as "system") over a simulation horizon of 20 quarters. Aggregating the shocks, we consider supply shocks $(\phi$ and $v)$ and demand disturbances ( $\varphi$ and $\eta)$.

\section{Table 4}

The results are interesting in a number of respects. First, supply shocks are the most relevant source of macroeconomic fluctuations in all systems. Their contribution ranges from more than 70 percent in Argentina, Brazil and Mexico to around 60 percent in Bolivia. This finding is broadly consistent with the empirical evidence for developed economies. ${ }^{7}$ Second, a closer look at the contribution of structural disturbances to

\footnotetext{
${ }^{7}$ Bergman (1996), for instance, using a bivariate VAR model for output and inflation, shows that more than one half of the macroeconomic fluctuations in the G7 countries are due to supply shocks at the typical business cycle frequency (the twenty-quarter horizon).
} 
fluctuations of individual variables shows the existence of three distinct groups of countries. The results for Argentina, Bolivia and Mexico reveal that productivity shocks are the main driving forces of relative productivity and relative private output variability, while relative labour services and the real exchange rate fluctuations are mainly governed by labour input and fiscal shocks, respectively. By contrast, while fiscal shocks still represent the main driving forces of the variability of international competitiveness in the Chilean economy, relative preference (labour input) disturbances turn out to drive variability in the dynamics of relative private output (productivity and labour services). Finally, in just-identified structures (Brazil and Mexico), we observe that relative productivity and relative labour services fluctuations originate from productivity shocks, with labour input and fiscal shocks dominating the variability of private output and real exchange rates changes. Third, focusing on the main variable of interest in our analysis (the real exchange rate) we find evidence of a difference in behaviour between overidentified and exactly identified systems: in the former class of models international competitiveness is driven by the demand-side of the economy, whilst in the latter group of countries the real exchange rate responds mostly to supply-side disturbances. Further, fiscal shocks are the main driving force of real exchange rate movements in the majority of cases (Argentina, Bolivia and Mexico), ranging from 60 to 90 percent, while they are less relevant for Chile and Peru, even though their effects are still sizeable (35 and 21 percent, respectively). Only in the case of Brazil is the contribution of this shock negligible.

\subsection{Fiscal shocks and international competitiveness of the LA countries}

The estimated models can be used to assess the effects of mutually orthogonal one-off structural shock on the dynamics of individual variables by calculating the impulse response functions (IRFs). In particular, we focus on the effects of an unanticipated relative fiscal shock on the international competitiveness of the LA countries. Tervala (2006) points out that, as government spending may exhibit different degrees of productivity, if this is low or zero, a rise in government spending causes a fall in domestic consumption, leading to a relative consumption change, which decreases the relative demand for domestic money, and consequently the real exchange rate depreciates. These 
predictions are coherent with the conclusions in Obstfeld and Rogoff (1995). On the other hand, if the productivity of government spending is sufficiently high, domestic consumption rises more than foreign consumption. Hence, the nominal and real exchange rate appreciate because the relative consumption change increases the relative demand for domestic money in a way consistent with the implications of Keynesian-style twocountry models of the world economy. ${ }^{8}$

Figure 1 shows the response of the real exchange rate (solid line) to a positive relative fiscal shock for each of the six LA countries. 95 percent confidence bounds (dashed lines), generated by Monte Carlo with 5000 replications, are also reported. The simulation horizon for IRFs is set equal to 20 quarters.

\section{Figure 1}

As can be seen, the Argentine real exchange rate appreciates after a relative fiscal shock. The loss in international competitiveness is consistent with the conclusions of Roldós (1995), according to whom public spending shocks can lead to real exchange rate appreciation. Since confidence bounds include the baseline path (the horizontal axis), deviations from the pre-shock level cannot be judged to be statistically significant at the chosen significance level in the fifth year of the simulation horizon. By contrast, in the models of Bolivia, Chile and Mexico we observe that fiscal shocks lead to real depreciation, albeit the deviations from the steady-state level for the Bolivian case appear to be statistically significant only in the first five quarters. Following the lines of reasoning of Tervala (2006), this finding may suggest low productivity of government spending policies in these two countries. The response of the Brazilian real exchange rate appears not to be statistically significant, consistently with the evidence discussed in the previous sub-Section. Finally, in the case of Peru we observe a statistically significant but short-lived depreciation of the real exchange rate.

\footnotetext{
${ }^{8}$ The international transmission of fiscal policy shocks in micro-founded general equilibrium models crucially depends on assumptions related to whether the fiscal shock is permanent or temporary, whether international asset markets are complete or not (Baxter, 1995), whether labor supply is fixed or variable, and how government purchases (Bianconi and Turnovsky, 1997) are financed. On this topic, see Arin and Koray (2008).
} 
In brief, the results from the IRFs suggest a close relationship between relevance of fiscal shocks as a driving source for real exchange rate fluctuations and effects of unanticipated fiscal shocks on the level of international competitiveness in the LA economies. The sign of the response of international competitiveness to this type of shock cannot as clearly be determined ex-ante. The evidence reported here indicates a substantial inelasticity of international competitiveness to shocks originating from public spending policies in countries where fiscal shocks have scant role in explaining real exchange variability. On the other hand, fiscal shocks may induce either real exchange rate appreciation (for Argentina) or depreciation (for Bolivia, Mexico and Chile) in the real exchange rate.

\subsection{Explaining real exchange dynamics in LA countries over the years 1980-2006}

This sub-Section describes how to assess the observed real exchange rates patterns for our six LA countries in the light of historical shifts in their fundamentals. Indeed, the existence of a stable long-run relationship among the variables of each model does not prevent the relative weight of those factors from changing over time in response to complex and interrelated reciprocal influences. Hence, it could be instructive to examine the hypothetical time path of international competitiveness if all disturbances had been associated to only one source of shock.

Table 5 summarises the relevance of each structural component in explaining international competitiveness variability over time. OLS estimates are obtained by regressing changes in the real exchange rate on its component driven by individual orthogonal shocks according to the decomposition (12). Since structural components are mutually orthogonal by construction, the total variation of the regressand (changes in international competitiveness) must be fully captured by the explanatory variables (supply shocks, $\phi$ and $v$, and demand disturbances, $\varphi$ and $\eta$ ).

\section{Table 5}

The results indicate that the in-sample variability of the real exchange rate is dominated by demand shocks in most of the models, with percentages ranging from 39 percent in the case of Chile to 92 percent in that of Bolivia. In particular, for five out of the six countries (Brazil being the only exception), fiscal shocks account for a 
considerable percentage of real exchange rate movements, ranging from one-fifth (for Peru) to four-fifth (for Mexico) of total variability. Also, notice that in most cases (Argentina, Bolivia, Mexico and Peru) the effects of fiscal impulses are stronger than those of productivity shocks. Finally, the relative importance of the temporary components (namely, preference shocks) varies across countries, being at its highest in Brazil, where it explains 43 percent of the historical variance (the effects of fiscal shocks being negligible), and in Peru, where the corresponding share is 34 percent, whilst is countries such as Mexico and Chile it is as low as 6.13 and 6.47 respectively.

In order to check for possible shifts in the relative explanatory contribution of shocks for real exchange rate changes over the sample span, we use a rolling method, i.e. we employ the estimated models to replicate the previous exercise over the window embracing the period from the first available observation to $1994 q 4$ and then extending it by a datapoint at a time. Summary statistics (mean, standard error of the mean, minimum and maximum values) for each system are reported in Table 6.

\section{Table 6}

The results broadly confirm the previous evidence in a number of ways. First, fiscal shocks are the most relevant source of variation for real exchange rates in the overidentified models. Second, in all models, the mean values of each shock resulting from the rolling procedure are quantitatively very close to their full-sample counterparts and qualitatively similar to the results from the forecast error variance decomposition exercise. Third, the standard error of the mean, as well as the minimum-maximum range, suggest that the relative contribution of the four driving forces in explaining real exchange rate changes are almost constant over time.

The last piece of evidence concerns the relationship between structural shocks and the pattern over time of the level of international competitiveness. Figure 1 shows, for each country, the real exchange rate series purged of the deterministic part (solid line), and its component explained by the fiscal shocks (dashed line).

\section{Figure 2}

Visual inspection suggests the following. It seems that the effects of fiscal shocks in the period 1981-1986 are considerable for all the countries under examination. After this period, however, this is still the case only in the models of Bolivia and Mexico, while in 
Chile and Peru long swings in the real exchange rate are only partially caused by the fiscal components. Consistently with the previous results, fiscal shocks do not appear to have significant explanatory power for real exchange rate movements in Brazil.

Combining this evidence with the results of the IRF analysis, we can conclude that in the cases where the real exchange rate depreciates in response to a relative fiscal shock (namely, Bolivia, Chile, Mexico and Peru), the explanatory power of these structural shocks is more pronounced over the entire investigation period. In the case of Argentina, where the IRF analysis shows the opposite result (that is, a real appreciation in response to a relative fiscal shock), the time path of the real exchange rate is less influenced by the component caused by this shock. According to Tervala (2006), the different time paths followed by the component of real exchange rates driven by fiscal shocks can be explained by the different degree of productivity of government expenditure in each country. ${ }^{9}$

\section{Robustness}

The results from structural VAR models relying on long-run restrictions may vary considerably depending on the exact specification of the empirical model. As argued by Faust and Leeper (1997), identification procedures, which involve restrictions on the long-run effects of structural shocks, may imply that type-II errors are more likely in confidence intervals because of the imprecision of the long-run parameter estimates. Therefore, in this section we study the robustness of the results discussed above with respect to changes in the empirical specification of the systems.

Three alternative empirical specifications are estimated in order to investigate how the relative weights of demand shocks (and in particular fiscal shocks) vary with the nature of the fluctuations. We filter the data by different methods, namely first differences, $F D$, the HP filter (Hodrick and Prescott, 1997), HP, and linear detrending,

\footnotetext{
${ }^{9}$ As shown by Rodriguez and Romero (2007), in Argentina the hyperinflation phenomenon which took place at the beginning of the 1990 and the following abolition of the currency board explain the dominant effect of the variability of transitory components on the behaviour of the real exchange rate, while in the case of Brazil (where the initially floating exchange rate was subsequently fixed) international competitiveness has mainly been driven by real shocks in the last decade.
} 
$L D$. In particular, $F D$ series are used to isolate short cycle fluctuations, $H P$-filtered series for intermediate frequencies and $L D$ series for low frequencies. We expect the role of demand shocks to decrease with the persistence of shocks. ${ }^{10}$ Notice that all alternative specifications neglect the existence of possible cointegration relationships. Thus, our robustness checks can shed light on the consequences of ignoring the presence of longrun equilibrium relationships between the variables.

Table 7 presents the results from imposing the over-identifying long-run restriction in the three alternative empirical specifications. $p$-values are in square brackets.

\section{Table 7}

Overall, the long-run structure implied by our theoretical relationship of reference is not rejected by the data in nine (one at the 1 percent, one at the 5 percent and the remaining seven at the 10 percent level of significance) out of eighteen cases. In particular, the outcome from the $F D$ specification is fully consistent with the baseline design, even though the test statistics are slightly less supportive of our economic priors. In the present context, this conclusion is not surprising since the $F D$ specification produces loss of relevant information, in the presence of documented cointegration relationships. Notice, further, that in the $L D$ specification we observe the rejection of the null hypothesis in all models but one (the Chilean case).

Following the same criterion as in the previous Section, we perform a forecast error variance decomposition under the over-identified structure for the specifications where the over-identifying restriction holds, but employing the just-identified structure when the constraint imposed on the long-run matrix is rejected by the data. The simulation horizon is set equal to 20 quarters. Table 8 shows the contribution (in percentage terms) of aggregate demand shocks and fiscal shocks to the overall forecast error variance of the real exchange rate under the three alternative empirical specifications.

\section{Table 8}

As expected, in most cases the relative importance of demand shocks is stronger in the specification where the short-run cycle frequency, $F D$, is isolated, and decreases

\footnotetext{
${ }^{10}$ The $F D$ specification is the baseline model (10) with $\Pi=0$ and with four common trends. Such a specification is consistent with the conclusions of the maximum eigenvalue test for Brazil, Chile and Mexico.
} 
when a longer cyclical component is taken into account, that is when we move from the $H P$ to the $L D$ specification.

Comparing these results to those from the VEC models, we observe that the explanatory power of demand shocks under the alternative specifications is greater than their counterparts from the baseline specification with cointegration. Moreover, focusing on the individual demand shocks, there is evidence of a bigger role for relative preference shocks, these now becoming the most important source for real exchange rate fluctuations.

As shown by Alexius (2005), the lack of the long run-equilibrium conditions between fundamental variables and the real exchange rate eliminates the relationship between the latter and productivity disturbances. Thus, the relative system impact of supply disturbances tends to decrease. In addition, if the long-run properties of the system are not properly taken into account, the effects of fiscal shocks are underestimated, as the relationship between government size and the dynamics of the real exchange rate is overlooked.

\section{Conclusions}

This paper adopts a modelling approach aimed at assessing the role of a wide class of underlying (structural) disturbances in driving real exchange rates (defined relative to the US dollar) in six LA countries (Argentina, Bolivia, Brazil, Chile, Mexico and Peru), along the lines of the studies of Ahmed et al. (1993) and Hoffmaister and Roldós (2001). These disturbances are identified as relative productivity, labour, fiscal and preference shocks.

Using quarterly data over the period 1980-2006, we analyse the case of the LA economies, for which the effects of fiscal shocks on the real exchange rate had not previously been studied. Specifically, we show that fiscal shocks are a key determinant of changes in international competitiveness for most of the countries we consider. Our approach sheds new light on the driving forces of real exchange rate dynamics in developing economies. A simpler modelling strategy, relying exclusively on a standard permanent/transitory decomposition, would provide only partial evidence, as, by 
construction, it would allow for only two types of shocks, ignoring the possibility of a wider class of disturbances hitting the economy as a whole (and consequently the real exchange rate as well) that also need to be investigated.

Therefore, our contribution to the literature on fiscal shocks is two-fold. First, we identify fiscal shocks in a multicountry/multivariate time series context, allowing for the existence of possible cointegration relationship among the variables of the system. Second, we present some new empirical evidence for six Latin American countries. We find that the effects of unanticipated fiscal impulses on the level of the real exchange rate vary, reflecting different degrees of government expenditures productivity. Further, using alternative econometric specifications, we show how the importance of fiscal shocks (and more in general of demand shocks) on the variability of the international competitiveness varies with the frequency of cyclical fluctuations isolated in the models. The explanatory power of demand shocks increases when shorter cyclical fluctuations are taken into account. Moreover, neglecting the presence of cointegration, which in fact holds in our case, amounts to overlooking the linkage between productivity and government spending and the real exchange rate. As we show, this leads to overestimating the role of demand shocks and underestimating the contribution of fiscal disturbances, putting into question the reliability of earlier evidence for which this criticism is relevant (see, e.g. Ahmed et al., 1993; Chowdhury, 2004; Hoffmaister and Roldós, 2001; Rodríguez and Romero, 2007). 


\section{References}

Ahmed S. (2003), Sources of Economic Fluctuations in Latin America and Implications for Choice of Exchange Rate Regimes, Journal of Development Economics, 72, p. $181-202$

Ahmed S., Ickes B.W., Wang P. and Yoo, B.S. (1993), International Business Cycle, American Economic Review, 83, p. 335-359.

Alexius A. (2005), Productivity Shocks and Real Exchange Rates, Journal of Monetary Economics, 52, p. 555-566.

Arin K.P. and Koray, F. (2008), Beggar Thy Neighbour? The Transmission of Fiscal Shocks from US to Canada, Open Economies Review, forthcoming.

Asea P.K. and Mendoza E.G. (1994), The Balassa-Samuelson Model: A GeneralEquilibrium Appraisal, Review of International Economics, 2, p. 244-267.

Baxter M. (1992), Fiscal Policy, Specialization, and Trade in the Two-Sector Model: The Return of Ricardo?, Journal of Political Economy, 100(4), 713-744.

Berg A., Borensztein E. and Mauro P. (2002), An Evaluation of Monetary Regime Options for Latin America, IMF Working Paper, 211.

Bergman, M. (1996), International Evidence on the Sources of Macroeconomic Fluctuations, European Economic Review, 40, p. 1237-1258.

Bianconi M. and Turnovsky S.J. (1997), International Effects of Government Expenditure in Interdependent Economies, Canadian Journal of Economics, 30, p. $57-84$.

Binder M. and Pesaran M.H. (1999), Stochastic Growth Models and their Econometric Implications, Journal of Economic Growth, 4, p. 139-83.

Blanchard O. and Quah D. (1989), The Dynamic Effects of Aggregate Demand and Supply Disturbances, American Economic Review, 79, p. 655-673.

Blanchard O. and Perotti R. (2002), An Empirical Characterization of the Dynamic Effects of Changes in Government Spending and Taxes on Output, Quarterly Journal of Economics, 117, p. 1329-1368.

Burnside C., Eichembaum M. and Fisher J.D.M. (2004), Fiscal Shocks and Their Consequences, Journal of Economic Theory, 115, p. 89-117. 
Busato F., Girardi A. and Argentiero A. (2005), Technology and Non-technology Shocks in a Two-sector Economy, 11.

Chang Y. and Hong, J.H. (2005), Do Technological Improvements in the Manufacturing Sector Raise Or Lower Employment?, American Economic Review, 96, p. 352368.

Chowdhury I.S. (2004), Sources of Exchange Rate Fluctuations: Empirical Evidence from Six Emerging Market Countries, Applied Financial Economics, p. 697-705.

Christiano L.J., Eichenbaum M. and Evans C.L. (1999), Monetary Policy Shocks: What Have We Learned and to what End?, in: Taylor J.B. and Woodford M. (eds.), Handbook of Macroeconomics, p. 65-148.

Clarida R.H. and Gali J. (1994), Sources of Real Exchange Rate Fluctuations: How Important Are Nominal Shocks?, Carnegie-Rochester Conference Series on Public Policies, 41, p. 1-56.

Dickey D.A. and Fuller W.A. (1979), Distribution of the estimators for autoregressive time series with a unit root, Journal of the American Statistical Association 74, p. 427-431.

Edwards S. (1988), Real and Monetary Determinants of Real Exchange Rate Behaviour: Theory and Evidence for Developing Countries, NBER Working Paper, 2721.

Edwards S. (1989), Capital Flows, Real Exchange Rates and Capital Controls: Some Latin America Experiences, NBER Working Paper, 6800.

Enders W. and Hurn S. (1994), Theory and Tests of Generalized Purchasing-Power Parity: Common Trends and Real Exchange Rates in the Pacific Rim, Review of International Economics, 2, p. 179-190.

Faust J. and Leeper E.M. (1997), When Do Long-Run Identifying Restrictions Give Reliable Results?, Journal of Business \& Economic Statistics, 15, p. 345-353.

Favero, C. (2002), How Do European Monetary and Fiscal Authorities Behave?, CEPR Discussion paper, 3426.

Gali, J. (1999), Technology, Employment, and the Business Cycle: Do Technology Shocks Explain Aggregate Fluctuations?, American Economic Review, 89, p. 249271 
Garratt A., Lee K., Pesaran M.H. and Shin Y. (2003), A Long-Run Structural Macroeconometric Model of the UK, Economic Journal, 113, p. 412-455.

Hemming R., M. Kell and S. Mahfouz (2002), The Effectiveness of Fiscal Policy in Stimulating Economic Activity: A Review of the Literature", IMF Working Paper, 208.

Hodrick R.J. and Prescott E.C. (1997), Postwar U.S. Business Cycles: An Empirical Investigation, Journal of Money, Credit and Banking, 29, p. 1-16.

Hoffmaister A.W. and Roldos J.E. (2001), The Sources of Macroeconomic Fluctuations in Developing Countries: Brazil and Korea, Journal of Macroeconomics, 23, p. 213-39.

Johansen, S. (1992), Cointegration in Partial Systems and the Efficiency of Singleequation Analysis, Journal of Econometrics, 52, p. 389-402.

Johansen, S. (1995), Likelihood-Based Inference in Cointegrated Vector Autoregressive Models, Oxford University Press, Oxford.

Krugman P. (1979), A Model of Balance of Payments Crises, Journal of Money, Credit, and Banking, 11, p. 311-325.

Kwiatkowski D., Phillips P.C.B., Schmidt P. and Shin Y. (1992), Testing the Null of Stationarity against the Alternative of a Unit Root: How Sure Are we that Economic Time Series Have a Unit Root?, Journal of Econometrics, 54, p. 159178.

Lee T. and Tse Y. (1996), Cointegration Tests with Conditional Heteroskedasticity, Journal of Econometrics, 73, p. 401-410.

Lucas R.E. (1982), Interest rates and currency prices in a two-country world, Journal of Monetary Economics, 10 (3), 335-359.

MacKinnon, J.G. (1996), Numerical Distribution Functions for Unit Root and Cointegration Tests, Journal of Applied Econometrics, 11, 601-618.

Mountford A. and Uhlig H. (2005), What Are the Effects Fiscal Policy Shocks?, SBF Discussion Paper, 39.

Obstfeld M. (1993), Model Trending Real Exchange Rates, Centre for International and Development Economics Research (CIDER) Working Papers, 11.

Obstfeld M. and Rogoff K. (1995), The Mirage of Fixed Exchange Rates, The Journal of 
Economic Perspectives, 9 (4), p. 73-96.

Osterwald-Lenum, M. (1992), A Note with Quantiles of the Asymptotic Distribution of the Maximum Likelihood Cointegration Rank Test Statistics," Oxford Bulletin of Economics and Statistics, 54, 461-472.

Phillips P.C.B. and Perron P. (1988) Testing for a Unit Root in Time Series Regression, Biometrika, 75, p. 335-346.

Perotti R. (2002), Estimating the Effects of Fiscal Policy in OECD Countries, ECB Working Paper, 168.

Rodríguez G. and Romero I. (2007), The Role of Permanent and Transitory Components in the Fluctuations of Latin-American Real Exchange Rates, Applied Economics, p. $1-10$.

Roldòs J.E. (1995), Supply-side of Disinflation Programs, IMF Staff Papers, 42, p. 158183.

Romer C.D. and Romer D.H. (1989), Does Monetary Policy Matter? A New Test in the Spirit of Friedman and Schwartz, in Olivier J. Blanchard and Stanley Fischer,eds.: NBER macroeconomics annual: 1989. Cambridge,Mass. And London: MIT Press, 121,70 .

Sarno L. and Taylor M.P. (2002), Purchasing power parity and the real exchange rate, IMF Staff Papers, 49, p. 65-105.

Stockman A.C. (1980), A Theory of Exchange Rate Determination, Journal of Political Economy, 88, p. 673-698.

Taylor M.P. (2006), Real Exchange Rates and Purchasing Power Parity: Mean-reversion in Economic Thought, Applied Financial Economics, 16, p. 1-17.

Tervala J. (2006), Productive Government Spending and the International Transmission of Fiscal Policy, HECER Discussion Paper, 120.

Warne A. (1993), A Common Trends Model: Identification, Estimation and Inference, IIES Seminar Paper, Stockholm, Stockholm University, 555.

Weber A. (1997), Sources of Purchasing Power Disparities between the G3 Economies, Journal of the Japanese and International Economies, 11, 548-583. 
Table 1 - Construction of the variables

\begin{tabular}{cc}
\hline \hline Variable & \multicolumn{1}{c}{ Definition } \\
\hline Relative productivity & $\pi_{t}^{i}=\left(\ln Y_{t}^{i}-\ln N_{t}^{i}\right)-\left(\ln Y_{t}^{U S}-\ln N_{t}^{U S}\right)$ \\
Relative employment & $n_{t}^{i}=\ln N_{t}^{i}-\ln N_{t}^{U S}$ \\
Relative private output & $z_{t}^{i}=\ln \left[Y_{t}^{i}\left(1-G_{t}^{i}\right)\right]-\ln \left[Y_{t}^{U S}\left(1-G_{t}^{U S}\right)\right]$ \\
Real exchange rate & $q_{t}^{i}=\ln E_{t}^{i}+\left(\ln P_{t}^{U S}-\ln P_{t}^{i}\right)$ \\
\hline \hline
\end{tabular}

Note. For each variable the suffix $i$ refers to each Latin America country in turn, while the suffix US refers to the base country (the US economy). The subscript $t$ stands for time. 
Table 2 - Unit root tests

\begin{tabular}{|c|c|c|c|c|c|c|c|c|c|c|c|c|c|c|c|c|}
\hline & \multicolumn{4}{|c|}{$\pi$} & \multicolumn{4}{|c|}{$n$} & \multicolumn{4}{|c|}{$z$} & \multicolumn{4}{|c|}{$q$} \\
\hline & \multicolumn{2}{|c|}{ Levels } & \multicolumn{2}{|c|}{$\begin{array}{c}\text { First } \\
\text { differrences }\end{array}$} & \multicolumn{2}{|c|}{ Levels } & \multicolumn{2}{|c|}{$\begin{array}{c}\text { First } \\
\text { differrences }\end{array}$} & \multicolumn{2}{|c|}{ Levels } & \multicolumn{2}{|c|}{$\begin{array}{c}\text { First } \\
\text { differrences }\end{array}$} & \multicolumn{2}{|c|}{ Levels } & \multicolumn{2}{|c|}{$\begin{array}{c}\text { First } \\
\text { differrences }\end{array}$} \\
\hline & DP & TS & DP & TS & DP & TS & DP & TS & DP & TS & DP & TS & DP & $\mathrm{TS}$ & DP & TS \\
\hline Argentina & $\mathrm{c}, \mathrm{t}$ & -2.16 & $\mathrm{c}$ & -9.92 & $\mathrm{c}, \mathrm{t}$ & -2.42 & $\mathrm{c}$ & -4.35 & $\mathrm{c}$ & -1.94 & . & -4.13 & $\mathrm{c}, \mathrm{t}$ & -3.79 & $\mathrm{c}$ & -3.44 \\
\hline Bolivia & $\mathrm{c}, \mathrm{t}$ & -2.08 & $\mathrm{c}$ & -6.45 & $\mathrm{c}, \mathrm{t}$ & -2.01 & $\mathrm{c}$ & -4.74 & $\mathrm{c}, \mathrm{t}$ & -0.32 & $\mathrm{c}$ & -1.87 & $\mathrm{c}$ & -1.46 & . & -4.96 \\
\hline Brazil & $\mathrm{c}$ & -1.66 & . & -6.44 & $\mathrm{c}, \mathrm{t}$ & -2.18 & $\mathrm{c}$ & -5.19 & $\mathrm{c}$ & -1.73 & . & -3.70 & $\mathrm{c}$ & -1.24 & . & -4.63 \\
\hline Chile & $\mathrm{c}, \mathrm{t}$ & -2.05 & $\mathrm{c}$ & -7.94 & $\mathrm{c}, \mathrm{t}$ & -1.76 & $\mathrm{c}$ & -6.59 & $\mathrm{c}, \mathrm{t}$ & -2.86 & $\mathrm{c}$ & -3.63 & $\mathrm{c}, \mathrm{t}$ & -1.16 & $\mathrm{c}$ & -4.45 \\
\hline Mexico & $\mathrm{c}, \mathrm{t}$ & -1.76 & $\mathrm{c}$ & -5.73 & $\mathrm{c}, \mathrm{t}$ & -2.06 & $\mathrm{c}$ & -4.22 & $\mathrm{c}$ & -1.42 & . & -3.95 & $\mathrm{c}$ & -2.33 & . & -11.7 \\
\hline Peru & $\mathrm{c}, \mathrm{t}$ & -1.52 & c & -6.64 & $\mathrm{c}, \mathrm{t}$ & -0.03 & c & -5.43 & $\mathrm{c}$ & -1.49 & . & -2.70 & $\mathrm{c}$ & -1.95 & . & -4.74 \\
\hline
\end{tabular}

Note. ADF test statistics for the null hypothesis of a unit root process for the variables in the levels and in first differences are reported in columns "TS". The critical value at the 1 percent level of significance is 4.05 if a constant and a linear trend $(c, t)$ are included in the regression, -3.49 with only a constant term $(c)$ and -2.59 if no deterministic parts (-) are included. At the 5 percent level of significance these values are $3.45,-2.89$ and -1.94 , respectively (MacKinnon, 1996). The specification of the deterministic component is presented in the column "DP". Definitions of the variables are provided in Table 1. 
Table 3 - Cointegration rank

\begin{tabular}{cccccc}
\hline \hline & & \multicolumn{3}{c}{ Rank } \\
& Lags & & & \\
& & 0 & 1 & 2 & 3 \\
\hline Argentina & 4 & 66.77 & 28.53 & 11.03 & 1.87 \\
Bolivia & 8 & 69.77 & 31.16 & 11.77 & 0.42 \\
Brazil & 4 & 47.31 & 22.6 & 8.3 & 0.47 \\
Chile & 3 & 48.89 & 26.05 & 11.11 & 2.66 \\
Mexico & 2 & 49.48 & 27.07 & 11.47 & 0.63 \\
Peru & 5 & 56.06 & 28.68 & 4.64 & 0.74 \\
\hline \hline
\end{tabular}

Note. Critical values for the trace test statistics at the 95 percent for rank 0, 1, 2, 3 and 4 are 47.21, 29.68, 15.41 and 3.76, respectively, while at the 99 percent are 54.46, 35.65, 20.04 and 6.65, respectively (Osterwald-Lenum, 1992). The column "Lag" reports the number of lags included in the VAR specification suggested by the AIC. 
Table 4 - Forecast error variance decomposition

\begin{tabular}{|c|c|c|c|c|c|c|}
\hline & \multicolumn{4}{|c|}{ Individual shocks } & \multicolumn{2}{|c|}{ Nature of shocks } \\
\hline & \multicolumn{6}{|c|}{ Argentina } \\
\hline & $\phi$ & $v$ & $\varphi$ & $\eta$ & Supply & Demand \\
\hline$\Delta \pi$ & 82.80 & 1.68 & 11.87 & 3.65 & 84.48 & 15.52 \\
\hline$\Delta n$ & 0.96 & 97.46 & 0.37 & 1.21 & 98.42 & 1.58 \\
\hline$\Delta z$ & 87.24 & 11.96 & 0.69 & 0.11 & 99.20 & 0.80 \\
\hline$\Delta q$ & 16.13 & 8.99 & 60.69 & 14.19 & 25.12 & 74.88 \\
\hline \multirow[t]{3}{*}{ System } & 46.78 & 30.02 & 18.41 & 4.79 & 76.81 & 23.19 \\
\hline & \multicolumn{6}{|c|}{ Bolivia } \\
\hline & $\phi$ & $v$ & $\varphi$ & $\eta$ & Supply & Demand \\
\hline$\Delta \pi$ & 50.58 & 5.43 & 34.82 & 9.17 & 56.01 & 43.99 \\
\hline$\Delta n$ & 7.61 & 91.93 & 0.12 & 0.34 & 99.54 & 0.46 \\
\hline$\Delta z$ & 70.68 & 6.14 & 19.16 & 4.02 & 76.82 & 23.18 \\
\hline$\Delta q$ & 3.32 & 0.71 & 90.77 & 5.20 & 4.03 & 95.97 \\
\hline \multirow[t]{3}{*}{ System } & 33.05 & 26.05 & 36.22 & 4.68 & 59.10 & 40.90 \\
\hline & \multicolumn{6}{|c|}{ Brazil } \\
\hline & $\phi$ & $v$ & $\varphi$ & $\eta$ & Supply & Demand \\
\hline$\Delta \pi$ & 90.77 & 4.67 & 0.73 & 3.83 & 95.44 & 4.56 \\
\hline$\Delta n$ & 67.84 & 26.20 & 2.92 & 3.04 & 94.04 & 5.96 \\
\hline$\Delta z$ & 6.90 & 17.83 & 69.03 & 6.24 & 24.73 & 75.27 \\
\hline$\Delta q$ & 22.73 & 61.64 & 0.48 & 15.15 & 84.37 & 15.63 \\
\hline \multirow[t]{3}{*}{ System } & 47.06 & 27.59 & 18.29 & 7.07 & 74.65 & 25.36 \\
\hline & \multicolumn{6}{|c|}{ Chile } \\
\hline & $\phi$ & $v$ & $\varphi$ & $\eta$ & Supply & Demand \\
\hline$\Delta \pi$ & 20.06 & 47.70 & 6.02 & 26.22 & 67.76 & 32.24 \\
\hline$\Delta n$ & 11.56 & 82.91 & 0.28 & 5.25 & 94.47 & 5.53 \\
\hline$\Delta z$ & 43.83 & 6.77 & 1.69 & 47.71 & 50.60 & 49.40 \\
\hline$\Delta q$ & 23.76 & 27.85 & 34.82 & 13.57 & 51.61 & 48.39 \\
\hline \multirow[t]{3}{*}{ System } & 24.80 & 41.31 & 10.70 & 23.19 & 66.11 & 33.89 \\
\hline & \multicolumn{6}{|c|}{ Mexico } \\
\hline & $\phi$ & $v$ & $\varphi$ & $\eta$ & Supply & Demand \\
\hline$\Delta \pi$ & 86.20 & 0.65 & 0.97 & 12.18 & 86.85 & 13.15 \\
\hline$\Delta n$ & 2.49 & 95.96 & 0.07 & 1.48 & 98.45 & 1.55 \\
\hline$\Delta z$ & 70.92 & 25.75 & 2.52 & 0.81 & 96.67 & 3.33 \\
\hline$\Delta q$ & 17.52 & 1.63 & 78.35 & 2.50 & 19.15 & 80.85 \\
\hline \multirow[t]{3}{*}{ System } & 44.28 & 31.00 & 20.48 & 4.24 & 75.28 & 24.72 \\
\hline & \multicolumn{6}{|c|}{ Peru } \\
\hline & $\phi$ & $v$ & $\varphi$ & $\eta$ & Supply & Demand \\
\hline$\Delta \pi$ & 67.42 & 22.32 & 2.86 & 7.40 & 89.74 & 10.26 \\
\hline$\Delta n$ & 67.32 & 25.31 & 3.78 & 3.59 & 92.63 & 7.37 \\
\hline$\Delta z$ & 7.35 & 13.03 & 64.80 & 14.82 & 20.38 & 79.62 \\
\hline$\Delta q$ & 23.35 & 39.07 & 21.05 & 16.53 & 62.42 & 37.58 \\
\hline System & 41.36 & 24.93 & 23.12 & 10.59 & 66.29 & 33.71 \\
\hline
\end{tabular}

Note. Average percentage contribution of each structural shock in explaining variable fluctuations over a simulation horizon of 20 quarters. $\phi, v, \varphi, \eta$ indicate relative productivity, relative labour, relative fiscal and relative preference shocks, respectively. The column "Supply" is the aggregate contribution of $\phi$ and $v$ disturbances. The column "Demand" is the aggregate contribution of $\varphi$ and $\eta$ disturbances. The row "System" indicates the average contribution of individual shocks and aggregate disturbances, disentangled according to their nature, for the whole system. 
Table 5 - Historical decomposition

\begin{tabular}{ccccccc}
\hline \hline & \multicolumn{3}{c}{ Individual shocks } & \multicolumn{3}{c}{ Nature of shocks } \\
& $\phi$ & $v$ & $\varphi$ & $\eta$ & Supply & Demand \\
\hline Argentina & 19.07 & 24.65 & 35.35 & 20.93 & 43.72 & 56.28 \\
Bolivia & 5.21 & 2.90 & 73.36 & 18.53 & 8.11 & 91.89 \\
Brazil & 15.51 & 39.87 & 1.25 & 43.37 & 55.38 & 44.62 \\
Chile & 39.11 & 21.89 & 32.53 & 6.47 & 61.00 & 39.00 \\
Mexico & 10.98 & 2.04 & 80.85 & 6.13 & 13.02 & 86.98 \\
Peru & 17.82 & 27.11 & 21.02 & 34.05 & 44.93 & 55.07 \\
\hline \hline
\end{tabular}

Note. Percentage contribution of each structural shock in explaining the historical variance of the real exchange rate quarterly changes. $\phi, v, \varphi, \eta$ indicate relative productivity, relative labour, relative fiscal and relative preference shocks, respectively. The column "Supply" is the aggregate contribution of $\phi$ and $v$ disturbances. The column "Demand" is the aggregate contribution of $\varphi$ and $\eta$ disturbances. 
Table 6 - Historical decomposition - Rolling Method

\begin{tabular}{|c|c|c|c|c|}
\hline & \multicolumn{4}{|c|}{ Argentina } \\
\hline & $\phi$ & $v$ & $\varphi$ & $\eta$ \\
\hline Mean & 19.07 & 22.24 & 38.93 & 19.76 \\
\hline Std. err. of mean & 0.05 & 0.22 & 0.33 & 0.14 \\
\hline Minimum & 18.23 & 19.65 & 34.92 & 17.80 \\
\hline \multirow[t]{3}{*}{ Maximum } & 20.08 & 25.16 & 42.27 & 21.71 \\
\hline & \multicolumn{4}{|c|}{ Bolivia } \\
\hline & $\phi$ & $v$ & $\varphi$ & $\eta$ \\
\hline Mean & 2.59 & 2.53 & 79.07 & 15.81 \\
\hline Std. err. of mean & 0.11 & 0.03 & 0.36 & 0.24 \\
\hline Minimum & 1.98 & 2.08 & 73.36 & 12.33 \\
\hline \multirow[t]{3}{*}{ Maximum } & 5.21 & 2.93 & 83.57 & 18.88 \\
\hline & \multicolumn{4}{|c|}{ Brazil } \\
\hline & $\phi$ & $v$ & $\varphi$ & $\eta$ \\
\hline Mean & 17.65 & 38.03 & 1.09 & 43.22 \\
\hline Std. err. of mean & 0.16 & 0.17 & 0.01 & 0.17 \\
\hline Minimum & 15.44 & 35.14 & 0.84 & 40.22 \\
\hline \multirow[t]{3}{*}{ Maximum } & 20.18 & 41.18 & 1.25 & 46.73 \\
\hline & \multicolumn{4}{|c|}{ Chile } \\
\hline & $\phi$ & $v$ & $\varphi$ & $\eta$ \\
\hline Mean & 39.98 & 22.03 & 31.05 & 6.94 \\
\hline Std. err. of mean & 0.14 & 0.10 & 0.13 & 0.06 \\
\hline Minimum & 38.04 & 20.77 & 28.73 & 6.10 \\
\hline \multirow[t]{3}{*}{ Maximum } & 42.51 & 23.70 & 32.87 & 7.65 \\
\hline & \multicolumn{4}{|c|}{ Mexico } \\
\hline & $\phi$ & $v$ & $\varphi$ & $\eta$ \\
\hline Mean & 10.32 & 1.87 & 82.70 & 5.11 \\
\hline Std. err. of mean & 0.03 & 0.02 & 0.12 & 0.08 \\
\hline Minimum & 9.87 & 1.66 & 80.85 & 3.93 \\
\hline \multirow[t]{3}{*}{ Maximum } & 10.98 & 2.17 & 84.53 & 6.13 \\
\hline & \multicolumn{4}{|c|}{ Peru } \\
\hline & $\phi$ & $v$ & $\varphi$ & $\eta$ \\
\hline Mean & 22.29 & 30.68 & 14.37 & 32.66 \\
\hline Std. err. of mean & 0.29 & 0.31 & 0.45 & 0.17 \\
\hline Minimum & 17.82 & 26.24 & 11.20 & 30.49 \\
\hline Maximum & 24.31 & 33.18 & 21.31 & 35.56 \\
\hline
\end{tabular}

Note. Percentage contribution of each structural shock in explaining the historical variance of the real exchange rate quarterly changes. $\phi, v, \varphi, \eta$ indicate relative productivity, relative labour, relative fiscal and relative preference shocks, respectively. Summary statistics computed over simulation windows of increasing size, extended by a datapoint at a time, are reported by rows. All windows start with the first available observation, but they have different ending quarters. The smallest window covers the period up to $1994 q 4$, while the largest window embraces the entire sample span. 
Table 7 - Robustness Analysis - Model specification

\begin{tabular}{cccc}
\hline \hline & \multicolumn{3}{c}{ Model specification } \\
& $F D$ & $H P$ & $L D$ \\
\hline Argentina & {$[0.01]$} & {$[0.24]$} & {$[0.00]$} \\
Bolivia & {$[0.30]$} & {$[0.00]$} & {$[0.00]$} \\
Brazil & {$[0.00]$} & {$[0.00]$} & {$[0.00]$} \\
Chile & {$[0.09]$} & {$[0.54]$} & {$[0.45]$} \\
Mexico & {$[0.10]$} & {$[0.41]$} & {$[0.00]$} \\
Peru & {$[0.00]$} & {$[0.65]$} & {$[0.00]$} \\
\hline \hline
\end{tabular}

Note. p-values from a $\chi^{2}$-distributed LR over-identifying test with one degree of freedom are reported in squared brackets. FD, HP and LD indicates first differences, HP (Hodrick and Prescott, 1997) and linear detrending filters, respectively. 
Table 8 - Robustness Analysis - Forecast error variance decompositions

Model specification

$F D$

$H P$

$L D$

\begin{tabular}{ccccccc} 
& $\begin{array}{c}\text { Demand } \\
\text { shocks }\end{array}$ & $\varphi$ & $\begin{array}{c}\text { Demand } \\
\text { shocks }\end{array}$ & $\varphi$ & $\begin{array}{c}\text { Demand } \\
\text { shocks }\end{array}$ & $\varphi$ \\
\hline Argentina & 79.31 & 2.20 & 83.02 & 6.62 & 43.17 & 14.22 \\
Bolivia & 94.48 & 21.24 & 82.46 & 12.26 & 89.05 & 7.64 \\
Brazil & 85.26 & 30.37 & 42.64 & 14.89 & 60.52 & 25.66 \\
Chile & 79.85 & 5.13 & 82.16 & 30.23 & 45.01 & 3.05 \\
Mexico & 91.51 & 7.61 & 63.33 & 4.18 & 17.29 & 2.06 \\
Peru & 89.23 & 5.52 & 45.60 & 0.40 & 27.78 & 2.06 \\
\hline \hline
\end{tabular}

Note. Average percentage contribution of demand and relative fiscal shocks $(\varphi)$ in explaining real exchange rate fluctuations at different cyclical frequencies over a simulation horizon of 20 quarters. FD, HP and LD indicates first differences, HP (Hodrick and Prescott, 1997) and linear detrending filters, respectively. 
Figure 1 -Response of the real exchange rate to a fiscal shock
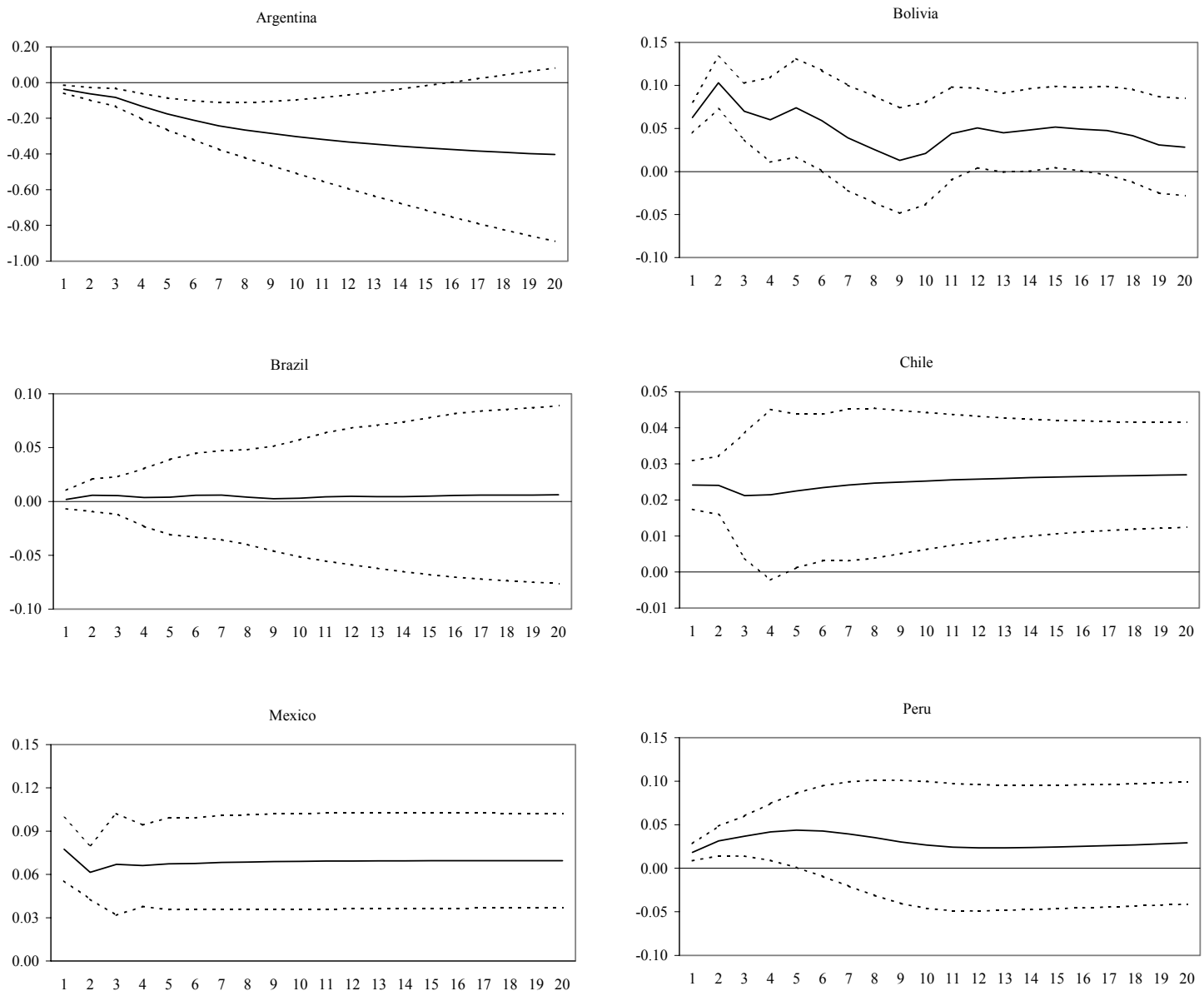

Note. Response of the real exchange rate to a relative fiscal shock. The vertical axis denotes changes from the pre-shock level (solid lines). The horizontal axis indicates quarters after the shocks. Confidence bounds (dashed lines) are generated by Monte Carlo with 5000 replications. 
Figure 2 - Real exchange rate dynamics and the component driven by the fiscal shock
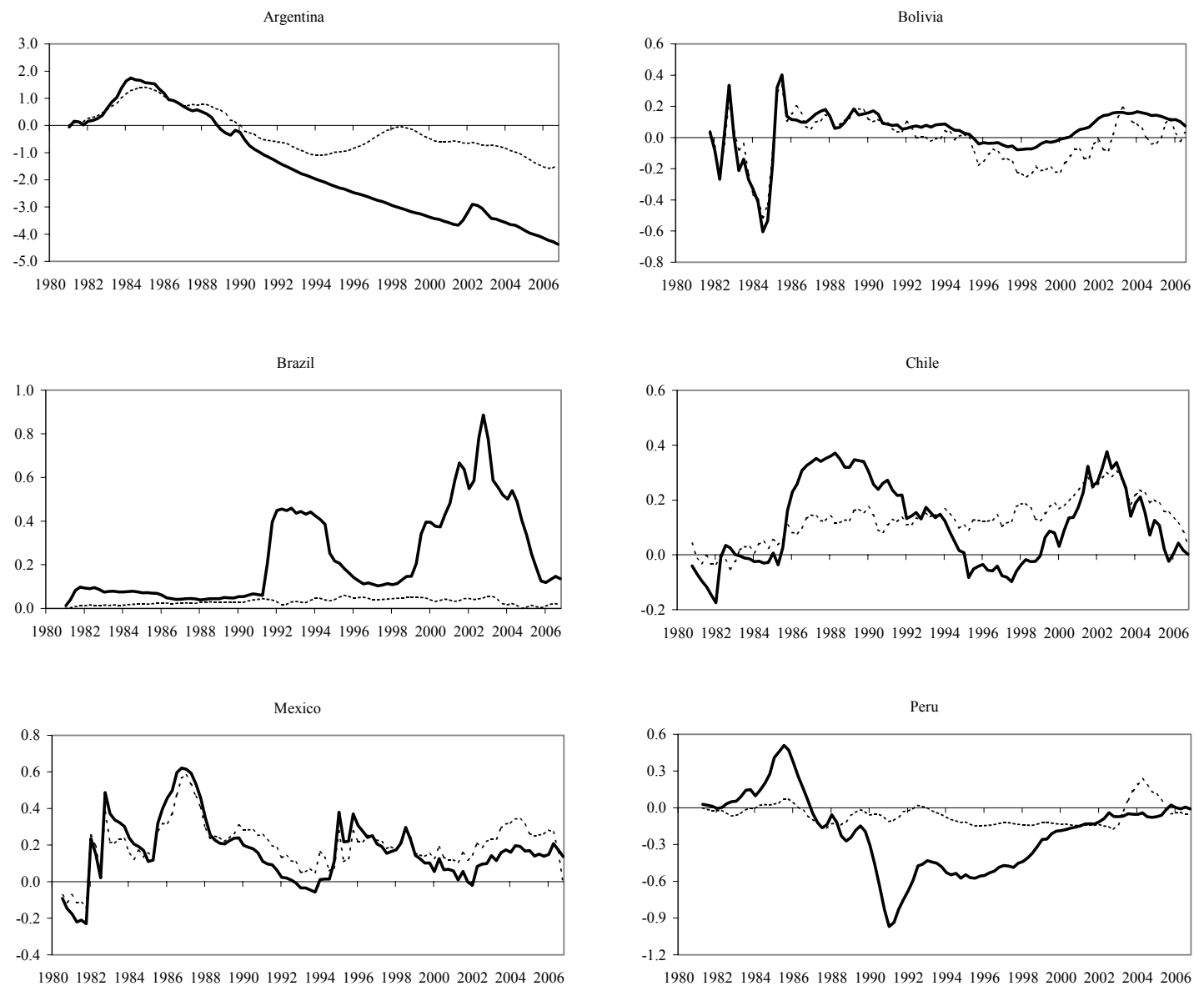

Note. In each graph, the dashed line indicates the real exchange rate, while the solid line plots its component driven by the fiscal shock. 